\title{
One-Pot Synthesis of $\beta$-Acetamido Ketones Using Boric Acid at Room Temperature
}

\author{
Zahed Karimi-Jaberi and Korosh Mohammadi \\ Department of Chemistry, Firoozabad Branch, Islamic Azad University, P.O. Box 74715-117, Fars, Firoozabad, Iran \\ Correspondence should be addressed to Zahed Karimi-Jaberi, zahed.karimi@yahoo.com
}

Received 3 October 2011; Accepted 14 November 2011

Academic Editors: H. Pellissier and D. B. Ramachary

Copyright $\odot 2012$ Z. Karimi-Jaberi and K. Mohammadi. This is an open access article distributed under the Creative Commons Attribution License, which permits unrestricted use, distribution, and reproduction in any medium, provided the original work is properly cited.

$\beta$-acetamido ketones were synthesized in excellent yields through one-pot condensation reaction of aldehydes, acetophenones, acetyl chloride, and acetonitrile in the presence of boric acid as a solid heterogeneous catalyst at room temperature. It is the first successful report of boric acid that has been used as solid acid catalyst for the preparation of $\beta$-acetamido ketones. The remarkable advantages offered by this method are green catalyst, mild reaction conditions, simple procedure, short reaction times, and goodto-excellent yields of products.

\section{Introduction}

During the last few years, multicomponent reactions (MCRs) have proved to be remarkably successful in generating molecular complexity in a single synthetic operation. These processes consist of two or more synthetic steps, which are performed without isolation of any intermediates, thus reducing time and saving both energy and raw materials. MCRs are powerful tools in the modern drug discovery process and allow fast, automated, and high throughput generation of organic compounds. Furthermore, a field of increasing interest is the synthesis of useful synthetic building blocks via MCRs chemistry. For this reason, the discovery of novel MCRs is of interest [1-3].

$\beta$-acetamido ketones are versatile intermediates in that their skeletons exist in a number of biologically or pharmacologically important compounds [4]. The best known route for the synthesis of these compounds is the DakinWest reaction [5], which involves the condensation of an amino acid with acetic anhydride in the presence of a base via an intermediate azlactone to give the acetamido ketones [6]. Bhatia et al. proposed another procedure for the formation of these compounds through the condensation of an aryl aldehyde, acetophenone, and acetyl chloride in acetonitrile in the presence of $\mathrm{CoCl}_{2}$ [7] or montmorillonite $\mathrm{K}-10$ clay [8]. Other catalysts such as heteropolyacids [9],
$\mathrm{HClO}_{4}-\mathrm{SiO}_{2}$ [10], $\mathrm{CeCl}_{3}$ [11], $\mathrm{ZnO}$ [12], cyanuric chloride [13], Amberlyst-15 [14], and $\mathrm{POCl}_{3} /$ Borax [15] have been used. Although these methods are valuable, most of them employ expensive catalysts, long reaction times, or harsh reaction conditions. Therefore, the introduction of new and efficient methods for this multicomponent reaction is still necessary.

Following our systematic studies directed toward the development of practical, safe, and environmentally friendly procedures for several important organic transformations [16-19], herein we describe an efficient method for the synthesis of $\beta$-acetamido ketones through the condensation of an aryl aldehyde, an acetophenone, acetyl chloride, and acetonitrile in the presence of boric acid at room temperature.

\section{Results and Discussion}

Boric acid $\left(\mathrm{H}_{3} \mathrm{BO}_{3}\right)$ is a useful and environmentally benign catalyst which has been successfully utilized in numerous reactions, for example, the aza-Michael addition [20], Biginelli reaction [21], transesterification of ethyl acetoacetate [22], Mannich reaction [23], and by our group in the synthesis of dibenzoxanthenes [16] and $\alpha$-aminophosphonates [17]. It offers milder conditions relative to common mineral 
<smiles>[R]c1ccc(C(=O)c2cccc(C(C)=O)c2)cc1</smiles>

SCHEME 1

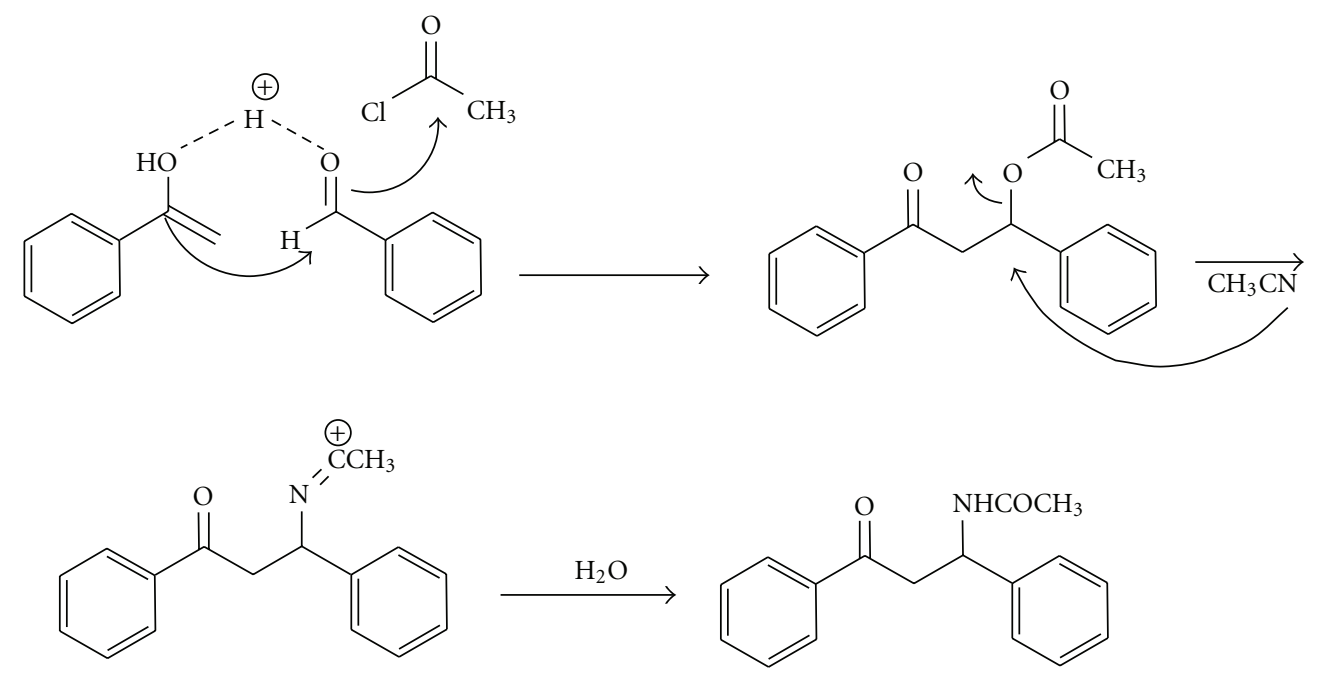

SCHEME 2

acids. Boric acid is a readily available and inexpensive reagent and can conveniently be handled and removed from the reaction mixture. Thus, the remarkable catalytic activities together with its operational simplicity make it the most suitable catalyst for the synthesis of $\beta$-acetamido ketones.

To optimize the reaction conditions, the reaction of benzaldehyde, acetophenone, acetyl chloride, and acetonitrile was used as a model reaction. The optimized reactant ratios were found to be 1.0 equiv. benzaldehyde, 1.0 equiv. acetophenone, 2 equiv. acetyl chloride, $4 \mathrm{~mL}$ acetonitrile, and $0.1 \mathrm{~g}$ of boric acid. The expected product was produced in $95 \%$ yield after $1.5 \mathrm{~h}$ at room temperature (Scheme 1). After completion of the reaction, the catalyst (boric acid) can easily be separated from the reaction mixture. To show the generality and scope of the boric acid-promoted $\beta$ acetamido ketones synthesis, the reaction was examined with various structurally diverse aldehydes and acetophenones. The results are summarized in Table 1. The structures of products were confirmed by comparison with their known physical and spectral (NMR and IR) data [6-13].

The suggested mechanism for this reaction is patterned in Scheme 2. We believe that boric acid is coordinated to the oxygen of the aldehyde and activate benzaldehyde for nucleophilic attack [11]. On the other hand, boric acid facilitates enolization of the acetophenone. The presence of acetyl chloride is necessary for the transformation since the reaction in its absence gave none of the desired product even after $2 \mathrm{~h}$. It is important to note that the synthesis of $\beta$ acetamido ketones could not be achieved in the absence of catalyst (boric acid).

\section{Conclusions}

In conclusion, this paper describes a convenient and efficient process for the synthesis of $\beta$-acetamido ketones through the condensation of an aryl aldehyde, an acetophenone, acetyl chloride, and acetonitrile in the presence of boric acid as a solid heterogeneous catalyst at room temperature. This method offers some advantages in terms of simplicity of performance, low reaction times, solvent-free condition, low cost, and it follows along the line of green chemistry. The catalyst is readily available and inexpensive and can conveniently be handled and removed from the reaction mixture. We believe that this procedure is convenient, economic, and a user-friendly process for the synthesis of $\beta$ acetamido ketones of biological and medicinal importance.

\section{Experimental}

4.1. General Procedure for Preparation of $\beta$-acetamido Ketones. A mixture of aldehyde $(2 \mathrm{mmol})$, acetophenone $(2 \mathrm{mmol})$, acetyl chloride $(2 \mathrm{mmol})$, acetonitrile $(4 \mathrm{~mL})$, and boric acid 
TABLE 1: Synthesis of $\beta$-acetamido ketones using boric acid.

\begin{tabular}{|c|c|c|c|c|c|}
\hline Entry & $\mathrm{R}$ & $\mathrm{R}^{\prime}$ & Product & Time (h) & Yield (\%) \\
\hline 1 & $\mathrm{H}$ & $\mathrm{H}$ & $3 a$ & 1.5 & 95 \\
\hline 2 & $\mathrm{H}$ & $4-\mathrm{Cl}$ & $3 b$ & 1.5 & 90 \\
\hline 3 & $\mathrm{H}$ & $4-\mathrm{NO}_{2}$ & $3 c$ & 3.5 & 97 \\
\hline 4 & $\mathrm{H}$ & $4-\mathrm{CH}_{3}$ & $3 d$ & 2 & 85 \\
\hline 5 & $4-\mathrm{Cl}$ & $\mathrm{H}$ & $3 e$ & 2 & 88 \\
\hline 6 & $4-\mathrm{Cl}$ & $4-\mathrm{Cl}$ & $3 f$ & 2 & 88 \\
\hline 7 & $4-\mathrm{Cl}$ & $4-\mathrm{NO}_{2}$ & $3 g$ & 2 & 90 \\
\hline 8 & $4-\mathrm{Cl}$ & $4-\mathrm{CH}_{3}$ & $3 h$ & 1.5 & 88 \\
\hline 9 & $4-\mathrm{CH}_{3}$ & $\mathrm{H}$ & $3 \mathbf{i}$ & 1.5 & 95 \\
\hline 10 & $4-\mathrm{CH}_{3}$ & $4-\mathrm{CH}_{3}$ & $3 \mathbf{j}$ & 2 & 92 \\
\hline 11 & $4-\mathrm{CH}_{3}$ & $4-\mathrm{NO}_{2}$ & $3 k$ & 2 & 98 \\
\hline 12 & $3-\mathrm{NO}_{2}$ & $\mathrm{H}$ & 31 & 3 & 90 \\
\hline 13 & $3-\mathrm{NO}_{2}$ & $4-\mathrm{Cl}$ & $3 m$ & 3.5 & 92 \\
\hline 14 & $4-\mathrm{NO}_{2}$ & $\mathrm{H}$ & $3 n$ & 3.5 & 91 \\
\hline 15 & $4-\mathrm{NO}_{2}$ & $4-\mathrm{Cl}$ & 30 & 2 & 92 \\
\hline 16 & $4-\mathrm{NO}_{2}$ & $4-\mathrm{NO}_{2}$ & $3 p$ & 3 & 87 \\
\hline 17 & $4-\mathrm{OH}$ & $\mathrm{H}$ & $3 q$ & 0.5 & 80 \\
\hline 18 & $4-\mathrm{CH}_{3} \mathrm{O}$ & $\mathrm{H}$ & $3 \mathbf{r}$ & 0.5 & 86 \\
\hline 19 & $2,3-\mathrm{Cl}_{2}$ & $\mathrm{H}$ & $3 s$ & 2.5 & 87 \\
\hline 20 & $2,3-\mathrm{Cl}_{2}$ & $4-\mathrm{Cl}$ & $3 t$ & 2 & 92 \\
\hline 21 & $2,4-\mathrm{Cl}_{2}$ & $4-\mathrm{NO}_{2}$ & $3 \mathbf{u}$ & 3.5 & 85 \\
\hline 22 & $2,6-\mathrm{Cl}_{2}$ & $\mathrm{H}$ & $3 v$ & 3 & 80 \\
\hline 23 & $2-\mathrm{Cl}-6-\mathrm{F}$ & $\mathrm{H}$ & $3 w$ & 4.5 & 80 \\
\hline 24 & 2-Cl-6-F & $4-\mathrm{NO}_{2}$ & $3 x$ & 4 & 88 \\
\hline 25 & $4-\mathrm{Cl}-3-\mathrm{NO}_{2}$ & $\mathrm{H}$ & $3 y$ & 2 & 90 \\
\hline
\end{tabular}

$(0.1 \mathrm{~g})$ was stirred at room temperature for the appropriate time indicated in Table 1 . The progress of reactions was monitored by TLC (ethyl acetate/n-hexane $=1 / 4$ ). After completion of the reaction, the reaction mixture was diluted with water and extracted with ethyl acetate, concentrated under vacuum, and the crude mixture was purified by recrystallization from ethyl acetate/n-hexane to give the pure product.

\subsection{Spectral Data for Selected Products}

4.2.1. $\beta$-acetamido- $\beta$-(4-chlorophenyl)-4-chloropropiophenone $3 f$. (Table 1, entry 6) mp $141-143^{\circ} \mathrm{C}$, IR $\left(\mathrm{KBr}, \mathrm{cm}^{-1}\right): 3264$, 3056, 1670, 1635, 1584, 1292, 1088, 885, 825, ${ }^{1} \mathrm{HNMR}$ $\left(\mathrm{CDCl}_{3}\right): \delta 2.08(\mathrm{~s}, 3 \mathrm{H}), 3.40(\mathrm{dd}, J=7.3$, and $10.9 \mathrm{~Hz}, 1 \mathrm{H})$, $3.82(\mathrm{dd}, J=7.3$, and $10.9 \mathrm{~Hz}, 1 \mathrm{H}), 5.57(\mathrm{~m}, 1 \mathrm{H}), 7.32(\mathrm{~s}$, $1 \mathrm{H}), 7.47(\mathrm{~d}, J=9.1 \mathrm{~Hz}, 4 \mathrm{H}), 7.90(\mathrm{~d}, J=9.1 \mathrm{~Hz}, 4 \mathrm{H})$.

4.2.2. $\beta$-acetamido- $\beta$-(2,3-dichlorophenyl)-4-chloropropiophenone $3 t$. (Table 1 , entry 20$) \mathrm{mp} 200-202^{\circ} \mathrm{C}, \operatorname{IR}\left(\mathrm{KBr}, \mathrm{cm}^{-1}\right)$ : 3291, 3077, 1690, 1651, 1589, 1547, 1401, 1370, 1298, 1225, 1197, 1091, 996, 816, 785, 742, 657. ${ }^{1} \mathrm{HNMR}\left(\mathrm{CDCl}_{3}\right): \delta$ $2.03(\mathrm{~s}, 3 \mathrm{H}), 3.42(\mathrm{dd}, J=5$, and $17.5 \mathrm{~Hz}, 1 \mathrm{H}), 3.72(\mathrm{dd}$, $J=5$, and $17.5 \mathrm{~Hz}, 1 \mathrm{H}), 5.82(\mathrm{~m}, 1 \mathrm{H}), 6.96(\mathrm{~d}, \mathrm{br}, J=$ $7.5 \mathrm{~Hz}, 1 \mathrm{H}), 7.12-7.43(\mathrm{~m}, 5 \mathrm{H}), 7.82(\mathrm{~d}, J=7.5 \mathrm{~Hz}, 2 \mathrm{H})$.
${ }^{13} \mathrm{CNMR}\left(\mathrm{CDCl}_{3}\right): \delta 23.33,41.01,48.49,126.46,127.38$, $129.10,129.54,133.56,134.57,140.34,169.44,197.45$.

\section{Acknowledgments}

The authors gratefully acknowledge the financial support from the Research Council of Islamic Azad University, Firoozabad Branch. They would also like to thank Ms. Baharak Pooladian for her kind help.

\section{References}

[1] A. Dömling and I. Ugi, "Multicomponent reactions with isocyanides," Angewandte Chemie International Edition, vol. 39, no. 18 , pp. 3168-3210, 2000.

[2] B. B. Touré and D. G. Hall, "Natural product synthesis using multicomponent reaction strategies," Chemical Reviews, vol. 109, no. 9, pp. 4439-4486, 2009.

[3] D. J. Ramón and M. Yus, "Asymmetric multicomponent reactions (AMCRs): the new frontier," Angewandte Chemie International Edition, vol. 44, no. 11, pp. 1602-1634, 2005.

[4] J. R. Casimir, C. Turetta, L. Ettouati, and J. Paris, "First application of the Dakin-West reaction of Fmoc chemistry: synthesis of the ketomethylene tripeptide Fmoc- $\mathrm{N}(\alpha)-\mathrm{Asp}(\mathrm{tBu})-$ $(\mathrm{R}, \mathrm{S})-\mathrm{Tyr}(\mathrm{tBu}) \Psi\left(\mathrm{Co}-\mathrm{CH}_{2}\right)$ Gly-OH," Tetrahedron Letters, vol. 36, no. 27, pp. 4797-4800, 1995.

[5] H. D. Dakin and R. West, "A general reaction of amino acids. II," Journal of Biological Chemistry, vol. 78, no. 3, pp. 745-756, 1928.

[6] G. L. Buchanan, “The Dakin-West reaction,” Chemical Society Reviews, vol. 17, pp. 91-109, 1988.

[7] B. Bhatia, M. M. Reddy, and J. Iqbal, "Cobalt-catalysed threecomponent coupling involving ketones or ketoesters, aldehydes and acetonitrile: a novel one-pot synthesis of $\beta$ acetamido ketones," Journal of the Chemical Society, Chemical Communications, no. 6, pp. 713-714, 1994.

[8] D. Bahulayan, S. K. Das, and J. Iqbal, "Montmorillonite K10 clay: an efficient catalyst for the one-pot stereoselective synthesis of $\beta$-acetamido ketones," Journal of Organic Chemistry, vol. 68, no. 14, pp. 5735-5738, 2003.

[9] E. Rafiee, F. Shahbazi, M. Joshaghani, and F. Tork, "The silica supported H3PW12O40 (a heteropoly acid) as an efficient and reusable catalyst for a one-pot synthesis of $\beta$-acetamido ketones by Dakin-West reaction," Journal of Molecular Catalysis A, vol. 242, no. 1-2, pp. 129-134, 2005.

[10] M. Nasr-Esfahani, M. Montazerozohori, and T. Gholampour, "Silica supported perchloric acid: a convenient and environmentally friendly catalyst for the one-pot multicomponent synthesis of $\beta$-acetamido ketones," Chinese Journal of Chemistry, vol. 29, no. 1, pp. 123-130, 2011.

[11] A. T. Khan, L. H. Choudhury, T. Parvin, and M. A. Ali, " $\mathrm{CeCl}_{3} \cdot 7 \mathrm{H}_{2} \mathrm{O}$ : an efficient and reusable catalyst for the preparation of $\beta$-acetamido carbonyl compounds by multicomponent reactions (MCRs)," Tetrahedron Letters, vol. 47, no. 46, pp. 8137-8141, 2006.

[12] Z. Mirjafary, H. Saeidian, A. Sadeghi, and F. M. Moghaddam, " $\mathrm{ZnO}$ nanoparticles: an efficient nanocatalyst for the synthesis of $\beta$-acetamido ketones/esters via a multi-component reaction," Catalysis Communications, vol. 9, no. 2, pp. 299-306, 2008.

[13] B. Das, M. Srilatha, B. Veeranjaneyulu, and B. R. Rao, "An efficient, one-pot, multicomponent synthesis of $\beta$-acetamido 
carbonyl compounds using cyanuric chloride in an aqueous medium," Synthesis, no. 5, Article ID Z22209SS, pp. 803-806, 2010.

[14] B. Das and K. R. Reddy, "Facile one-pot multicomponent synthesis of $\beta$-acetamido ketones with Amberlyst- 15 as heterogeneous catalyst," Helvetica Chimica Acta, vol. 89, no. 12, pp. 3109-3111, 2006.

[15] K. Gholivand, H. Jafari, and H. Adibi, "Simple and new method for the synthesis of $\beta$-acetamido ketones on a solid surface," Synthetic Communications, vol. 41, no. 12, pp. 17861793, 2011.

[16] Z. Karimi-Jaberi and M. Keshavarzi, "Efficient one-pot synthesis of 14-substituted-14H-dibenzo[a,j]xanthenes using boric acid under solvent-free conditions," Chinese Chemical Letters, vol. 21, no. 5, pp. 547-549, 2010.

[17] Z. Karimi-Jaberi and M. Amiri, "One-pot synthesis of $\alpha$ aminophosphonates catalyzed by boric acid at room temperature," Heteroatom Chemistry, vol. 21, no. 2, pp. 96-98, 2010.

[18] Z. Karimi-Jaberi, M. Amiri, and N. Sadeghi, "Sodium dihydrogen phosphate as an efficient catalyst for one-pot, threecomponent synthesis of $\alpha$-aminophosphonates under solventfree conditions at room temperature," Synthetic Communications, vol. 40, no. 19, pp. 2948-2953, 2010.

[19] Z. Karimi-Jaberi and R. Arjmandi, "Acetic acid-promoted, efficient, one-pot synthesis of 2,3- dihydroquinazolin-4(1H)ones," Monatshefte für Chemie, vol. 142, no. 6, pp. 631-635, 2011.

[20] M. K. Chaudhuri, S. Hussain, M. L. Kantam, and B. Neelima, "Boric acid: a novel and safe catalyst for aza-Michael reactions in water," Tetrahedron Letters, vol. 46, no. 48, pp. 8329-8331, 2005.

[21] S. Tu, F. Fang, C. Miao et al., "One-pot synthesis of 3,4dihydropyrimidin-2(1H)-ones using boric acid as catalyst," Tetrahedron Letters, vol. 44, no. 32, pp. 6153-6155, 2003.

[22] G. C. M. Kondaiah, L. A. Reddy, K. S. Babu et al., "Boric acid: an efficient and environmentally benign catalyst for transesterification of ethyl acetoacetate," Tetrahedron Letters, vol. 49, no. 1, pp. 106-109, 2008.

[23] C. Mukhopadhyay, A. Datta, and R. J. Butcher, "Highly efficient one-pot, three-component Mannich reaction catalysed by boric acid and glycerol in water with major "syn" diastereoselectivity," Tetrahedron Letters, vol. 50, no. 29, pp. 42464250, 2009. 


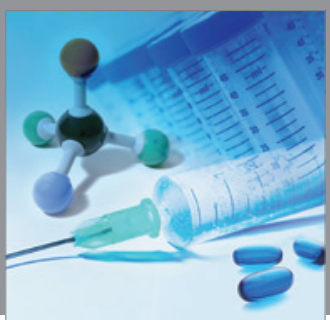

International Journal of

Medicinal Chemistry

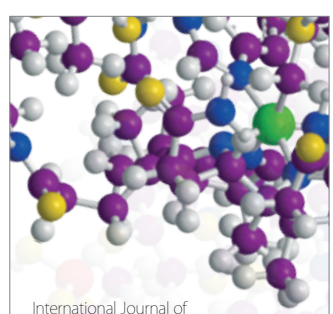

Carbohydrate Chemistry

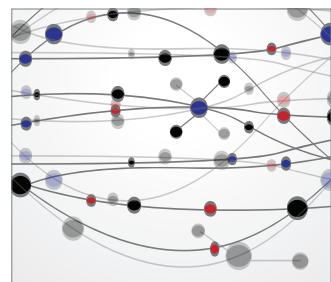

The Scientific World Journal
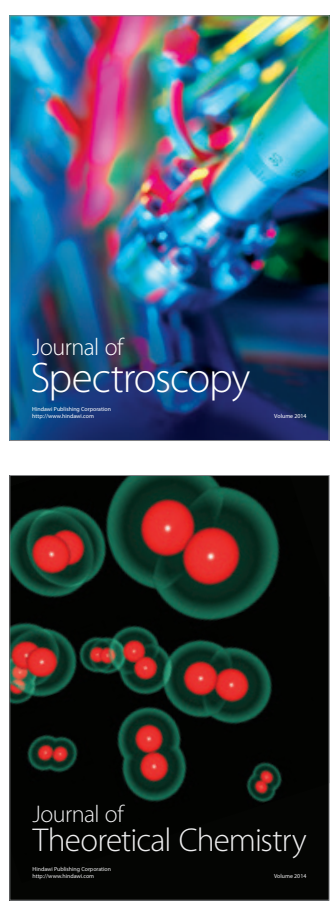
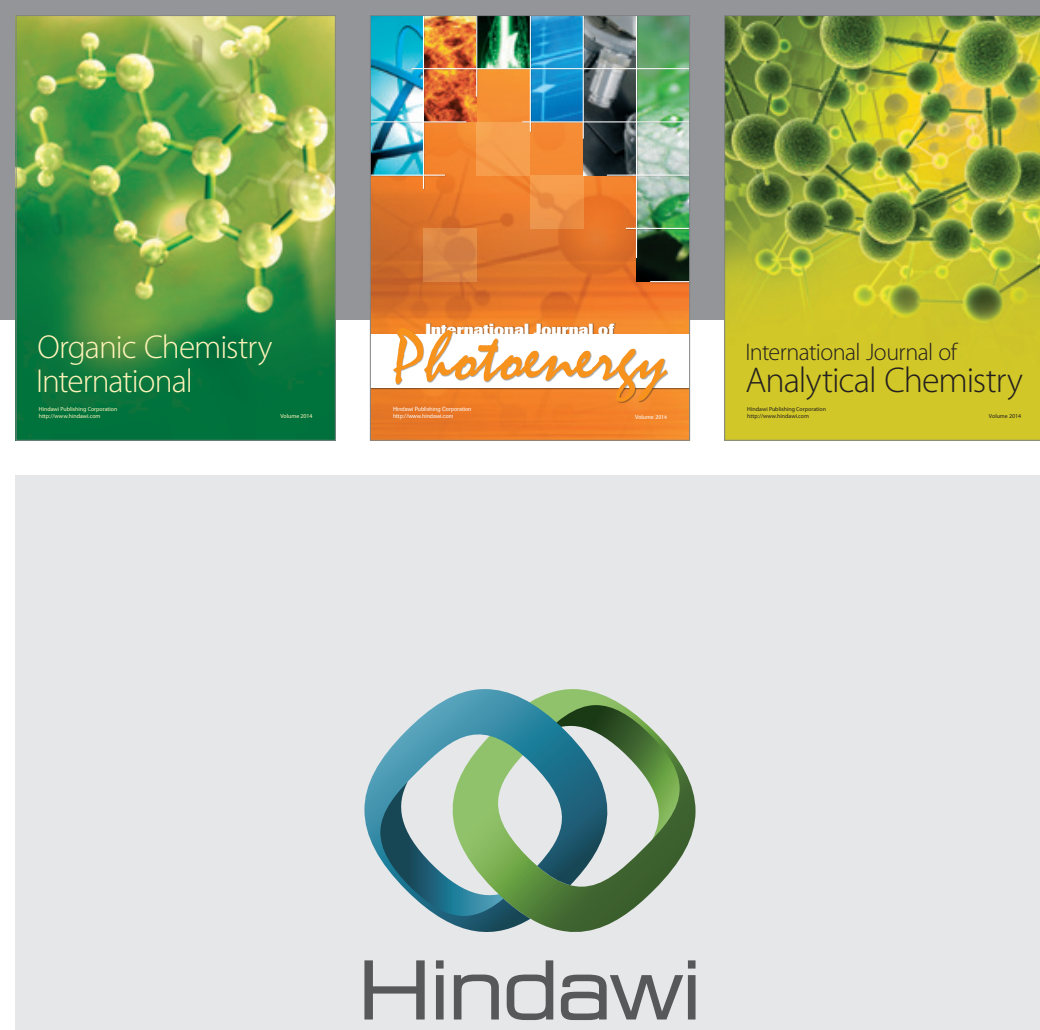

Submit your manuscripts at

http://www.hindawi.com
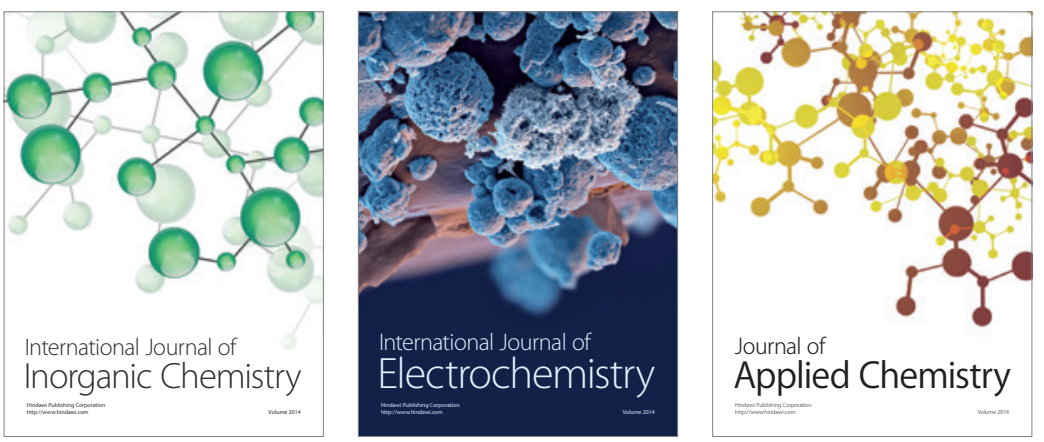

Journal of

Applied Chemistry
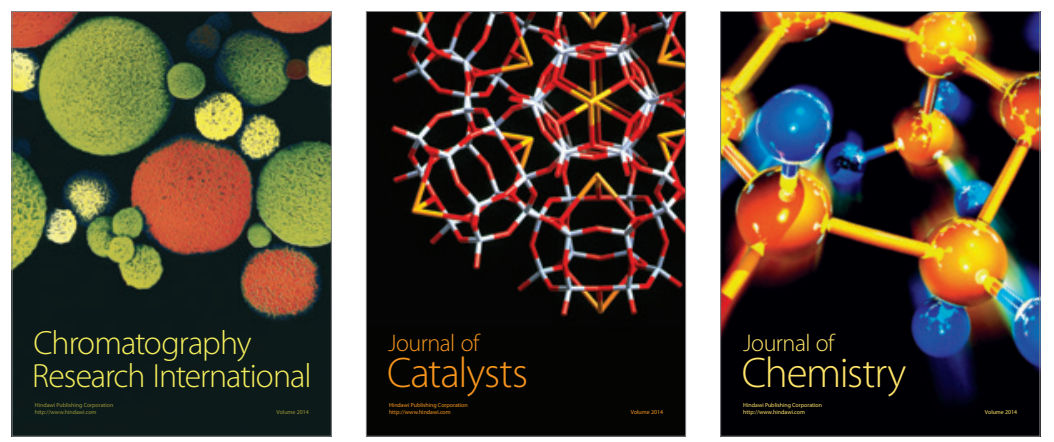
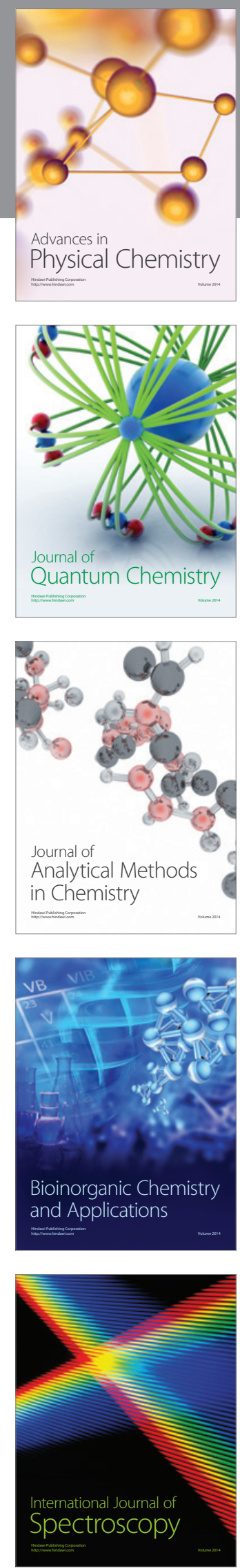